\title{
QUANTITATIVE ANALYSIS OF THE MISORIENTATION DISTRIBUTION AFTER THE RECRYSTALLISATION OF TENSILE DEFORMED COPPER SINGLE CRYSTALS
}

\author{
F. HAESSNER, ${ }^{*}$ K. SZTWIERTNIA* ${ }^{*}$ and P.-J. WILBRANDT** \\ * Institut für Werkstoffe der Technischen Universität Braunschweig, \\ Langer Kamp 8, D-W-3300 Braunschweig, Germany. \\ ** Institut für Metallphysik der Universität Göttingen, Hospitalstr. 3-5, \\ D-W-3400 Göttingen, Germany.
}

(Received July 10, 1990)

\begin{abstract}
Recrystallisation experiments in tensile deformed $\langle 100\rangle$ - and $\langle 111\rangle$-oriented single crystals of high purity copper yielded very accurate information about the orientations of recrystallised grains and deformation microstructure. For a statistical evaluation of the orientation relationships between the dominant recrystallised grains and the deformation microstructure the misorientation distribution function was calculated. The most frequently occurring orientation relationships can be described by coincidence relationships. Always several coincidence relationships are needed to characterise the results. The specimen treatment strongly influences the occurrence of the individual coincidence orientation relationships. A particularly preferred growth of grains with a $30^{\circ}$ or $40^{\circ}\langle 111\rangle$ orientation relationship was not observed.
\end{abstract}

KEY WORDS Copper, tensile deformation, recrystallisation, misorientation distribution, series expansion, Euler space, axis-angle space, $\Sigma$-boundaries

\section{INTRODUCTION AND DESCRIPTION OF THE PROBLEM}

Many properties of polycrystalline materials are influenced by the differences in orientation (misorientation) between neighbouring crystallites. In particular, we note that all those properties which depend on the character of grain boundaries belong to this group, for example segregation, corrosion, grain boundary stability. Moreover, information on misorientations can lead to better understanding of reactions in the solid state, as for example phase changes or recrystallisation phenomena.

A common question in primary recrystallisation is to what extent can certain recrystallised areas experience preferential growth by virtue of their orientation relationship to the deformed environment. Investigation of the orientation dependence of the grain boundary migration rate, carried out by Liebman et al. (1956), showed that recrystallised grains with a $40^{\circ}\langle 111\rangle$ orientation relationship to the deformation microstructure demonstrate preferential growth. The experiments were performed on mid-oriented aluminium crystals which were deformed under tensile stress. In recrystallisation experiments using tensile deformed $\langle 110\rangle$ oriented single crystals of copper and dilute copper-phosphorous alloys, pre- 
ferential growth of grains with such an orientation relationship was not observed, although appropriately oriented grains were found within the recrystallised structure (Wilbrandt, 1978; Wilbrandt and Haasen, 1980a, b; Berger, 1986; Berger et al., 1988). On the other hand, several investigations confirmed the preferential growth of $40^{\circ}\langle 111\rangle$ oriented grains in recrystallised aluminium (Senna and Lücke, 1976; Hirsch, 1988).

Considering those divergent results and controversies, both Ernst and Klement performed recrystallisation experiments on strained $\langle 100\rangle$ and $\langle 111\rangle$ oriented single crystals in order to determine the essential orientation relationships in the recrystallisation of copper (Ernst and Wilbrandt, 1984; Ernst, 1984; Klement and Wilbrandt, 1988; Klement et al., 1988). The evaluation of the results yielded a noticeable tendency for the preferential occurrence of certain orientation relationships between the recrystallised grains and the deformation microstructure. They were idealised by rotations of $22.6^{\circ}\langle 100\rangle, 21.8\langle 111\rangle, 48.8^{\circ}\langle 111\rangle$ and $129.8^{\circ}\langle 540\rangle$. These rotations correspond to coincidence orientation relationships with $\Sigma$ values of $13 a, 21 a, 19 b$ and $25 b$. In addition, the less deformed $\langle 111\rangle$ samples showed an orientation relationship characterised by a $145.7^{\circ}\langle 541\rangle$ rotation ( $\Sigma$ value of 23$)$. The results were purposely described by coincidence orientation relationships because in most cases the deviation of those orientation relationships actually found from these in particular was less than $6^{\circ}$.

A specific orientation relationship can be described in various symmetrically equivalent ways by rotations around mutual crystallographic axes. In an individual orientation relationship it does not matter which of the possible combinations was employed in the characterisation. The situation is quite different, however, for a frequency analysis of orientation relationships. Then the ambiguity of the various descriptions has to be removed. The combination of smallest angle of rotation with rotational axis in the standard (base) triangle 001-101-111 is such a singular reduction (Mackenzie, 1958). The first statistical analysis which takes these considerations into account was performed on misorientations in rolled copper (Pospiech et al., 1986).

In this paper the statistical method is applied to the analysis of the orientation relationships found in the above mentioned recrystallisation experiments by Ernst and Klement. In the discussion we shall particularly focus on the question whether a characterisation of the experimental orientation relationships by coincidence orientation relationships may be meaningful.

\section{CALCULATION AND REPRESENTATION OF MISORIENTATION DISTRIBUTION}

A misorientation can mathematically be represented by a multiplicity of mutually symmetric points lying in an orientation space. Of these points each one lies in a different sub-domain (base domain). Their number depends on the lattice symmetry of the material. In individual cases, a misorientation can be described by different orientation parameters. Their choice is made according to the nature of the problem (Ruer, 1976; Bunge, 1982; Haeßner et al. 1983; Frank, 1988). If for instance, as here, one is interested in the characterisation of the boundaries between two crystallites, then it is expedient to choose a description of the misorientation using axis and angle of rotation. Nevertheless, this representation of a misorientation is accompanied by strong non-linearities of the base domain. 
In general, when evaluating experimentally determined misorientations, one should of course take the limitations of accuracy of the data into account, caused by errors of measurement. Furthermore, as mentioned in the introduction, comparison of misorientations is only possible after they have been reduced to the same base domain of misorientation space.

If these factors are disregarded in an analysis of misorientations, false conclusions can be drawn in the interpretation of the misorientation statistics. These problems do not arise if the so-called Misorientation Distribution Function (MDF) is applied to the analysis of data.

$$
\frac{d I}{I} \equiv f(\Gamma) d \Gamma
$$

Here $d I$ is the grain boundary area between grains showing a misorientation $\Gamma$ within the interval $d \Gamma$, and $I$ is the total grain boundary area.

The function $f(\Gamma)$ can be expanded in a series of generalised spherical functions $i_{1}^{m n}(\Gamma)$, which are invariant with respect to the crystallite symmetry (Bunge and Weiland 1988):

$$
f(\Gamma)=\sum_{1} \sum_{m n} C_{1}^{m n} \ddot{T}_{1}^{m n}(\Gamma)
$$

The coefficients $C_{1}^{m n}$ may be calculated from the experimentally determined misorientations $\Gamma_{i}(i=1, \ldots, N)$ according to:

$$
C_{1}^{m n}=\frac{1}{N} \frac{\exp \left(-l^{2} \varepsilon_{0}^{2} / 4\right)-\exp (-l+1)^{2} \varepsilon_{0}^{2} / 4}{1-\exp \left(-\varepsilon_{0}^{2} / 4\right)} \sum_{i} T_{1}^{m n}\left(\Gamma_{i}\right)
$$

Here $\varepsilon_{0}$ characterises the scattering of a gaussian frequency distribution around each single misorientation $\Gamma_{i}$ (Pospiech and Lücke, 1975). Its value depends on the accuracy of the measurement. The coefficients $C_{1}^{m n}$ were determined up to $l_{\max }=34$ according to Eq. (3). The function $f(\Gamma)$ was then at first represented in Euler-space for reasons of the series technique. In the last step the MDF was then transformed to orientation space with rotational parameters $\omega, \vartheta, \psi$. Thereby $\omega$ symbolizes the angle of rotation, $\vartheta$ and $\psi$ are the spherical polar coordinates of the axis of rotation.

The Misorientation Distribution Function will be represented in the next section with the aid of cross sections $\omega=$ const. of the so-called base domain.

After Mackenzie (1958) the base domain is defined as follows: the angle of rotation is positive and the smallest of all possible angles of rotation. It is called the disorientation angle $\omega_{d}$. If both crystallites, whose mutual misorientation is to be calculated, exhibit cubic symmetry, then $0<\omega_{d}<62.8^{\circ}$ is true. All the axes of rotation $\left[r_{x}, r_{y}, r_{z}\right]$ lie in the standard triangle 001-101-111. The components of the axes of rotation are given by $r_{z} \geq r_{x} \geq r_{y} \geq 0$ with $r_{x}=\cos \psi \sin \vartheta, r_{y}=$ $\sin \psi \sin \vartheta, r_{z}=\cos \vartheta$.

\section{EXPERIMENTAL PROCEDURE AND RESULTS}

Since the recrystallisation experiments on tension deformed $\langle 100\rangle$ and $\langle 111\rangle$ oriented copper single crystals have been comprehensively described elsewhere 
(Ernst and Wilbrandt, 1984; Ernst, 1984; Klement, 1987; Klement and Wilbrandt, 1988), essential details only will be briefly summarized here. $\langle 100\rangle$ oriented single crystals were deformed by $10 \%$ and $20 \%$ respectively in a strain experiment. The extension of the $\langle 111\rangle$ oriented crystals was $4 \%$. Under these deformation conditions the crystals of both orientations show a uniformly oriented microstructure without deformation inhomogeneities. To generate recrystallisation nuclei the deformed samples were abraded at one end. After annealing, the orientations of the largest recrystallised grains were determined by the Laue technique and the orientation relationships to the deformation microstructure calculated. Tables 1 to 4 collate the results of the individual experiments.

Table 1 Orientation relationships between the recrystallised grains and the deformation microstructure $(\langle 100\rangle$-oriented crystals, $20 \%$ elongation, annealing temperature $750 \mathrm{~K})$

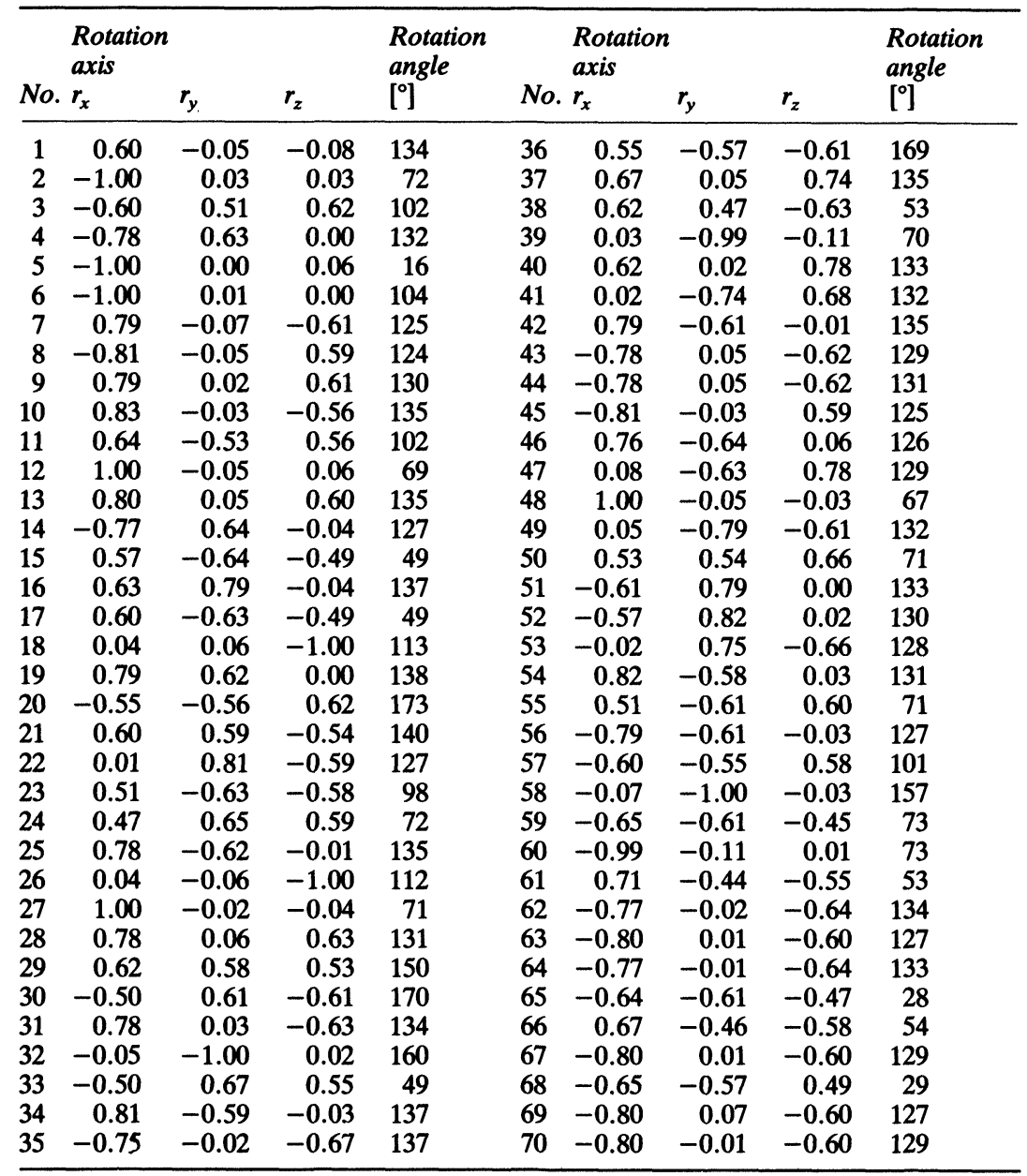


Table 2 Orientation relationships between the recrystallised grains and the deformation microstructure $(\langle 100\rangle$-oriented crystals, $10 \%$ elongation, annealing temperature $750 \mathrm{~K})$

\begin{tabular}{|c|c|c|c|c|c|c|c|c|c|}
\hline \multicolumn{4}{|c|}{$\begin{array}{l}\text { Rotation } \\
\text { axis }\end{array}$} & \multirow{2}{*}{$\begin{array}{l}\text { Rotation } \\
\text { angle } \\
\left.{ }^{\circ}\right]\end{array}$} & \multicolumn{3}{|c|}{$\begin{array}{l}\text { Rotation } \\
\text { axis }\end{array}$} & \multirow[b]{2}{*}{$r_{z}$} & \multirow{2}{*}{$\begin{array}{l}\text { Rotation } \\
\text { angle } \\
\left.{ }^{\circ}\right]\end{array}$} \\
\hline No & $r_{x}$ & $r_{y}$ & $r_{z}$ & & No. & $r_{x}$ & $r_{y}$ & & \\
\hline 1 & 0.75 & 0.01 & 0.66 & 133 & 13 & 0.08 & 0.99 & -0.08 & 68 \\
\hline 2 & -0.78 & -0.62 & -0.06 & 131 & 14 & -1.00 & 0.03 & 0.07 & 73 \\
\hline 3 & 0.03 & 1.00 & 0.00 & 156 & 15 & 0.77 & -0.63 & 0.04 & 134 \\
\hline 4 & -0.78 & -0.02 & -0.63 & 133 & 16 & 1.00 & -0.04 & 0.05 & 72 \\
\hline 5 & -0.83 & 0.55 & 0.04 & 130 & 17 & -0.07 & -0.81 & -0.53 & 133 \\
\hline 6 & 0.08 & 0.77 & -0.63 & 126 & 18 & 0.75 & -0.03 & 0.66 & 136 \\
\hline 7 & -0.02 & -1.00 & -0.04 & 114 & 19 & -0.69 & -0.47 & 0.56 & 53 \\
\hline 8 & 0.58 & 0.58 & 0.57 & 20 & 20 & 0.56 & 0.57 & 0.60 & 93 \\
\hline 9 & -0.78 & -0.03 & -0.63 & 133 & 21 & -0.06 & 0.78 & 0.62 & 127 \\
\hline 10 & 0.03 & 1.00 & 0.01 & 157 & 22 & 0.57 & -0.56 & -0.61 & 97 \\
\hline 11 & 0.69 & -0.47 & -0.55 & 50 & 23 & -0.99 & 0.12 & -0.05 & 115 \\
\hline 12 & -0.78 & -0.03 & -0.63 & 133 & 24 & -0.80 & -0.60 & -0.40 & 130 \\
\hline
\end{tabular}

Table 3 Orientation relationships between the recrystallised grains and the deformation microstructure $(\langle 100\rangle$-oriented crystals, $20 \%$ elongation, annealing temperature $1080 \mathrm{~K})$

\begin{tabular}{|c|c|c|c|c|c|c|c|c|c|}
\hline \multicolumn{3}{|c|}{$\begin{array}{l}\text { Rotation } \\
\text { axis }\end{array}$} & \multirow[b]{2}{*}{$r_{z}$} & \multirow{2}{*}{$\begin{array}{l}\text { Rotation } \\
\text { angle } \\
{\left[{ }^{\circ}\right]}\end{array}$} & \multicolumn{3}{|c|}{$\begin{array}{l}\text { Rotation } \\
\text { axis }\end{array}$} & \multirow[b]{2}{*}{$r_{z}$} & \multirow{2}{*}{$\begin{array}{l}\text { Rotation } \\
\text { angle } \\
{\left[{ }^{\circ}\right]}\end{array}$} \\
\hline No. & $r_{x}$ & $r_{y}$ & & & No. & $r_{x}$ & $r_{y}$ & & \\
\hline 1 & -0.03 & 0.62 & 0.79 & 135 & 12 & -0.77 & -0.63 & 0.02 & 132 \\
\hline 2 & 0.99 & 0.04 & -0.11 & 70 & 13 & 0.78 & -0.62 & 0.01 & 133 \\
\hline 3 & 0.81 & -0.59 & 0.04 & 131 & 14 & -0.79 & 0.03 & 0.61 & 134 \\
\hline 4 & -0.56 & 0.06 & 0.82 & 129 & 15 & 0.07 & -1.00 & 0.04 & 72 \\
\hline 5 & 0.80 & -0.60 & 0.00 & 133 & 16 & -0.57 & 0.56 & 0.60 & 132 \\
\hline 6 & 0.80 & 0.61 & 0.02 & 132 & 17 & -0.03 & -1.00 & 0.03 & 69 \\
\hline 7 & -0.82 & -0.57 & -0.03 & 132 & 18 & 0.61 & 0.48 & 0.63 & 45 \\
\hline 8 & 0.81 & 0.59 & 0.05 & 132 & 19 & 0.67 & 0.45 & 0.59 & 44 \\
\hline 9 & -0.56 & 0.64 & 0.53 & 169 & 20 & -0.81 & 0.05 & 0.58 & 136 \\
\hline 10 & 0.79 & -0.61 & 0.01 & 132 & 21 & 0.01 & -1.00 & 0.07 & 72 \\
\hline 11 & 0.09 & -0.99 & 0.05 & 71 & & & & & \\
\hline
\end{tabular}

Table 4 Orientation relationships between the recrystallised grains and the deformation microstructure $(\langle 111\rangle$-oriented crystals, $4 \%$ elongation, annealing temperature $750 \mathrm{~K})$

\begin{tabular}{|c|c|c|c|c|c|c|c|c|c|}
\hline \multicolumn{3}{|c|}{$\begin{array}{l}\text { Rotation } \\
\text { axis }\end{array}$} & \multirow[b]{2}{*}{$r_{z}$} & \multirow{2}{*}{$\begin{array}{l}\text { Rotation } \\
\text { angle } \\
{\left[{ }^{\circ}\right]}\end{array}$} & \multicolumn{3}{|c|}{$\begin{array}{l}\text { Rotation } \\
\text { axis }\end{array}$} & \multirow[b]{2}{*}{$r_{z}$} & \multirow{2}{*}{$\begin{array}{l}\text { Rotation } \\
\text { angle } \\
{\left[^{\circ}\right]}\end{array}$} \\
\hline No. & $r_{x}$ & $r_{y}$ & & & No. & $r_{x}$ & $r_{y}$ & & \\
\hline 1 & 0.99 & -0.12 & -0.02 & 135 & 8 & -0.67 & 0.00 & -0.74 & 151 \\
\hline 2 & -0.06 & -0.75 & -0.66 & 147 & 9 & 0.99 & -0.09 & -0.06 & 147 \\
\hline 3 & -0.65 & -0.75 & 0.11 & 146 & 10 & -0.62 & 0.11 & -0.78 & 150 \\
\hline 4 & 0.11 & 0.52 & 0.77 & 143 & 11 & 0.09 & -0.74 & 0.67 & 143 \\
\hline 5 & 0.60 & -0.79 & 0.10 & 144 & 12 & 0.58 & -0.81 & -0.09 & 144 \\
\hline 6 & 0.08 & -0.11 & -0.99 & 145 & 13 & 0.09 & -0.73 & 0.68 & 144 \\
\hline 7 & 0.75 & 0.09 & 0.66 & 145 & 14 & 0.10 & 0.60 & 0.80 & 133 \\
\hline
\end{tabular}


Table 4 (continued)

\begin{tabular}{|c|c|c|c|c|c|c|c|c|c|}
\hline \multicolumn{3}{|c|}{$\begin{array}{l}\text { Rotation } \\
\text { axis }\end{array}$} & \multirow[b]{2}{*}{$r_{z}$} & \multirow{2}{*}{$\begin{array}{l}\text { Rotation } \\
\text { angle } \\
\left.{ }^{\circ}\right]\end{array}$} & \multicolumn{3}{|c|}{$\begin{array}{l}\text { Rotation } \\
\text { axis }\end{array}$} & \multirow[b]{2}{*}{$r_{z}$} & \multirow{2}{*}{$\begin{array}{l}\text { Rotation } \\
\text { angle } \\
{\left[{ }^{\circ}\right]}\end{array}$} \\
\hline No. & $r_{x}$ & $r_{y}$ & & & No. & $r_{x}$ & $r_{y}$ & & \\
\hline 15 & 0.98 & 0.06 & 0.17 & 137 & 58 & -0.56 & 0.56 & 0.62 & 177 \\
\hline 16 & 0.98 & 0.06 & 0.18 & 136 & 59 & 0.80 & 0.07 & -0.59 & 129 \\
\hline 17 & -0.07 & 0.54 & -0.84 & 167 & 60 & 0.64 & 0.77 & 0.00 & 145 \\
\hline 18 & -0.09 & -0.15 & 0.98 & 136 & 61 & -0.64 & -0.06 & 0.77 & 35 \\
\hline 19 & 0.79 & 0.09 & 0.61 & 143 & 62 & -0.05 & -0.82 & -0.57 & 141 \\
\hline 20 & -0.99 & 0.17 & -0.01 & 130 & 63 & 0.68 & -0.14 & -0.71 & 20 \\
\hline 21 & -0.15 & 0.99 & -0.07 & 141 & 64 & -0.81 & 0.03 & -0.58 & 109 \\
\hline 22 & 0.05 & -0.61 & 0.86 & 166 & 65 & 0.05 & 0.62 & 0.78 & 111 \\
\hline 23 & -0.85 & 0.52 & -0.02 & 164 & 66 & -0.80 & 0.60 & 0.00 & 177 \\
\hline 24 & 0.76 & 0.13 & 0.64 & 140 & 67 & 0.71 & 0.15 & 0.69 & 27 \\
\hline 25 & 0.99 & -0.08 & -0.07 & 149 & 68 & -0.80 & -0.60 & 0.03 & 129 \\
\hline 26 & 0.05 & 0.55 & -0.84 & 92 & 69 & -0.80 & -0.04 & -0.59 & 112 \\
\hline 27 & 0.03 & 0.84 & 0.56 & 64 & 70 & -0.77 & -0.06 & -0.63 & 151 \\
\hline 28 & 0.07 & 0.81 & -0.59 & 47 & 71 & 0.01 & 1.00 & -0.06 & 158 \\
\hline 29 & 0.65 & -0.05 & -0.76 & 151 & 72 & -0.62 & -0.78 & -0.09 & 91 \\
\hline 30 & 0.04 & -0.60 & 0.80 & 135 & 73 & 0.80 & -0.60 & 0.04 & 95 \\
\hline 31 & -0.79 & -0.61 & 0.01 & 144 & 74 & 0.09 & 0.57 & -0.82 & 60 \\
\hline 32 & 0.80 & -0.61 & -0.01 & 89 & 75 & 0.59 & -0.03 & 0.80 & 172 \\
\hline 33 & 0.58 & 0.01 & -0.82 & 169 & 76 & 0.82 & 0.57 & -0.05 & 171 \\
\hline 34 & -0.03 & -0.77 & -0.63 & 54 & 77 & 0.86 & -0.50 & -0.09 & 55 \\
\hline 35 & 0.87 & 0.49 & -0.09 & 179 & 78 & 0.80 & 0.60 & 0.03 & 77 \\
\hline 36 & -0.04 & -0.77 & -0.64 & 56 & 79 & -0.78 & 0.63 & -0.04 & 148 \\
\hline 37 & 0.06 & 0.61 & 0.79 & 128 & 80 & 0.04 & 0.60 & 0.80 & 140 \\
\hline 38 & 0.76 & 0.56 & -0.03 & 81 & 81 & 1.00 & -0.02 & 0.04 & 137 \\
\hline 39 & 0.87 & 0.00 & 0.49 & 43 & 82 & 0.61 & 0.79 & -0.04 & 145 \\
\hline 40 & -1.00 & -0.06 & 0.07 & 149 & 83 & 0.79 & 0.60 & -0.11 & 93 \\
\hline 41 & 0.79 & -0.09 & 0.60 & 138 & 84 & 1.00 & 0.08 & 0.04 & 136 \\
\hline 42 & 0.01 & 0.08 & -1.00 & 142 & 85 & 0.83 & -0.01 & -0.55 & 100 \\
\hline 43 & 0.81 & 0.05 & 0.59 & 167 & 86 & -0.04 & -0.59 & -0.81 & 148 \\
\hline 44 & 0.05 & -0.61 & 0.79 & 166 & 87 & -0.04 & -0.59 & -0.81 & 149 \\
\hline 45 & 0.82 & 0.02 & 0.57 & 169 & 88 & 0.04 & 0.58 & -0.81 & 115 \\
\hline 46 & 0.79 & 0.04 & -0.61 & 128 & 89 & 0.81 & -0.59 & 0.00 & 175 \\
\hline 47 & -0.67 & -0.03 & -0.74 & 77 & 90 & -0.06 & 0.04 & 0.80 & 92 \\
\hline 48 & -0.04 & 0.00 & -1.00 & 169 & 91 & -0.71 & 0.09 & 0.70 & 34 \\
\hline 49 & 0.61 & -0.01 & -0.79 & 179 & 92 & -0.77 & 0.00 & 0.64 & 35 \\
\hline 50 & -0.79 & 0.00 & -0.61 & 108 & 93 & 0.76 & 0.04 & -0.65 & 147 \\
\hline 51 & -0.78 & 0.03 & -0.63 & 59 & 94 & -0.71 & 0.03 & 0.70 & 35 \\
\hline 52 & -0.81 & 0.59 & 0.02 & 99 & 95 & -0.70 & -0.03 & 0.71 & 32 \\
\hline 53 & -0.07 & 0.81 & 0.58 & 55 & 96 & 0.02 & 0.85 & -0.52 & 42 \\
\hline 54 & 0.02 & -0.85 & -0.53 & 164 & 97 & 0.12 & 0.84 & -0.53 & 41 \\
\hline 55 & -0.81 & 0.58 & 0.02 & 98 & 98 & 0.80 & -0.61 & -0.01 & 126 \\
\hline 56 & -0.01 & -0.85 & -0.53 & 165 & 99 & -0.89 & 0.46 & 0.02 & 20 \\
\hline 57 & 0.83 & 0.08 & 0.56 & 33 & & & & & \\
\hline
\end{tabular}

The limit of accuracy of the orientation determinations on recrystallised grains is $1^{\circ}$. The orientations of the crystal and with it the orientation of the deformation microstructure can be quoted with the same degree of accuracy. As a result, the uncertainty of the orientation relationships is estimated to be $3^{\circ}$. This value is also assumed in the calculation of the MDF for the scattering length $\varepsilon_{0}$ of the gaussian distribution around each single misorientation $\Gamma_{i}$. 
Using the data in Tables 1 to 4 the MDFs shown in the Figures 1 to 4 were calculated. Since every misorientation in each subdomain of the orientation space is represented by a point, only the base domain is shown. It encloses the whole standard triangle 001-101-111 up to rotation angles of $45^{\circ}$ and contracts on further increase of the angles of rotation to a strip along the symmetry line $\langle 101\rangle-\langle 111\rangle$. Individual sections through the base region were taken at $5^{\circ}$ intervals; the position of the maxima of the MDF is indicated by the contour lines.

According to the MDF plots, in no case at all do the misorientations exhibit a
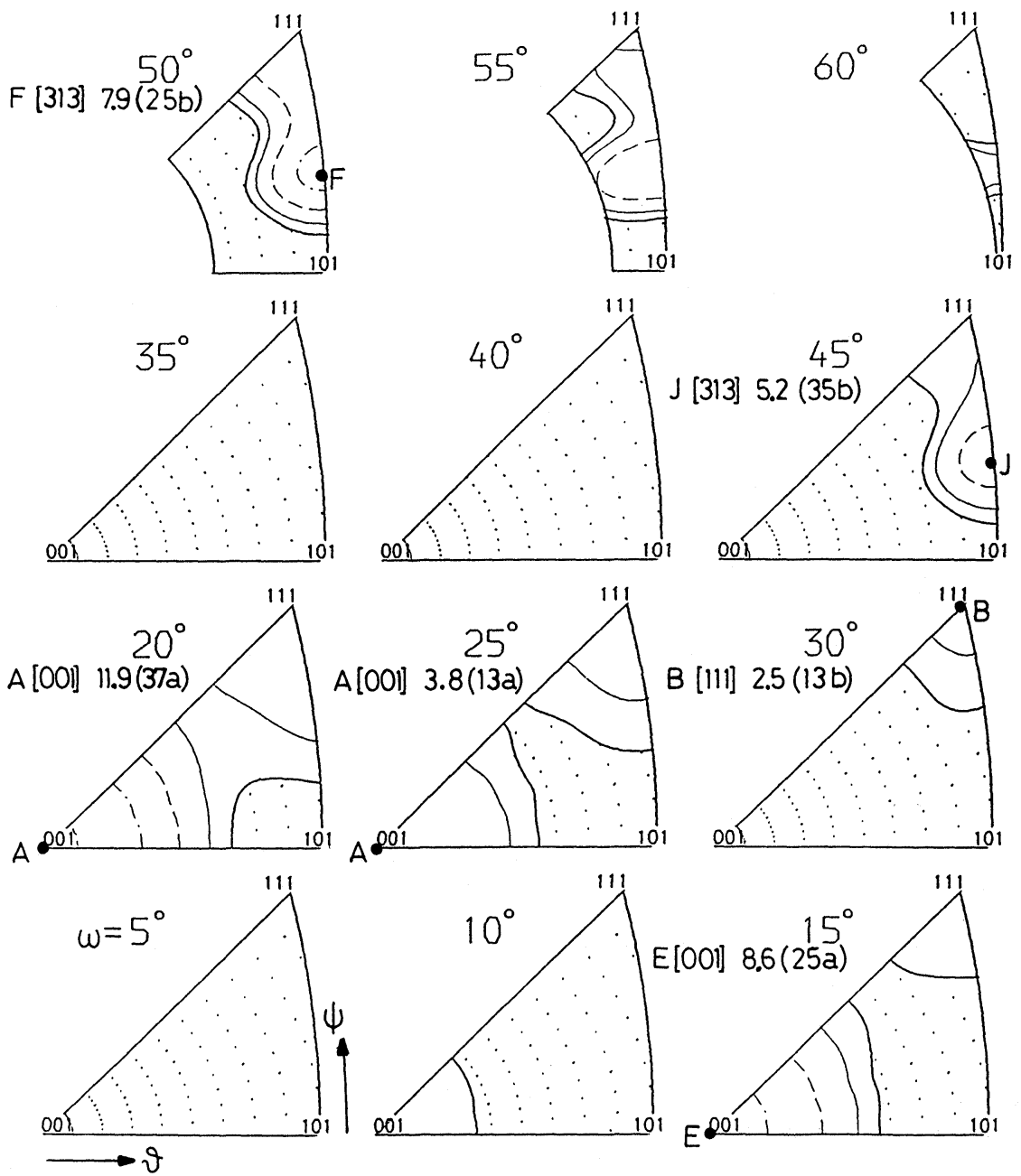

Figure 1 Misorientation distribution function of the largest recrystallised grains in tensile deformed copper single crystals after annealing $(\langle 100\rangle$-oriented crystals, $20 \%$ elongation, annealing temperature $750 \mathrm{~K} ; \mathrm{MDF}$ calculated for the data in Table 1: contour lines 1, 2, 4, 7, 11, 16, Regions under the level 1. are dotted. Maxima marked by: A, B, etc., axis notation, value of the MDF, value of $\Sigma$ ). 

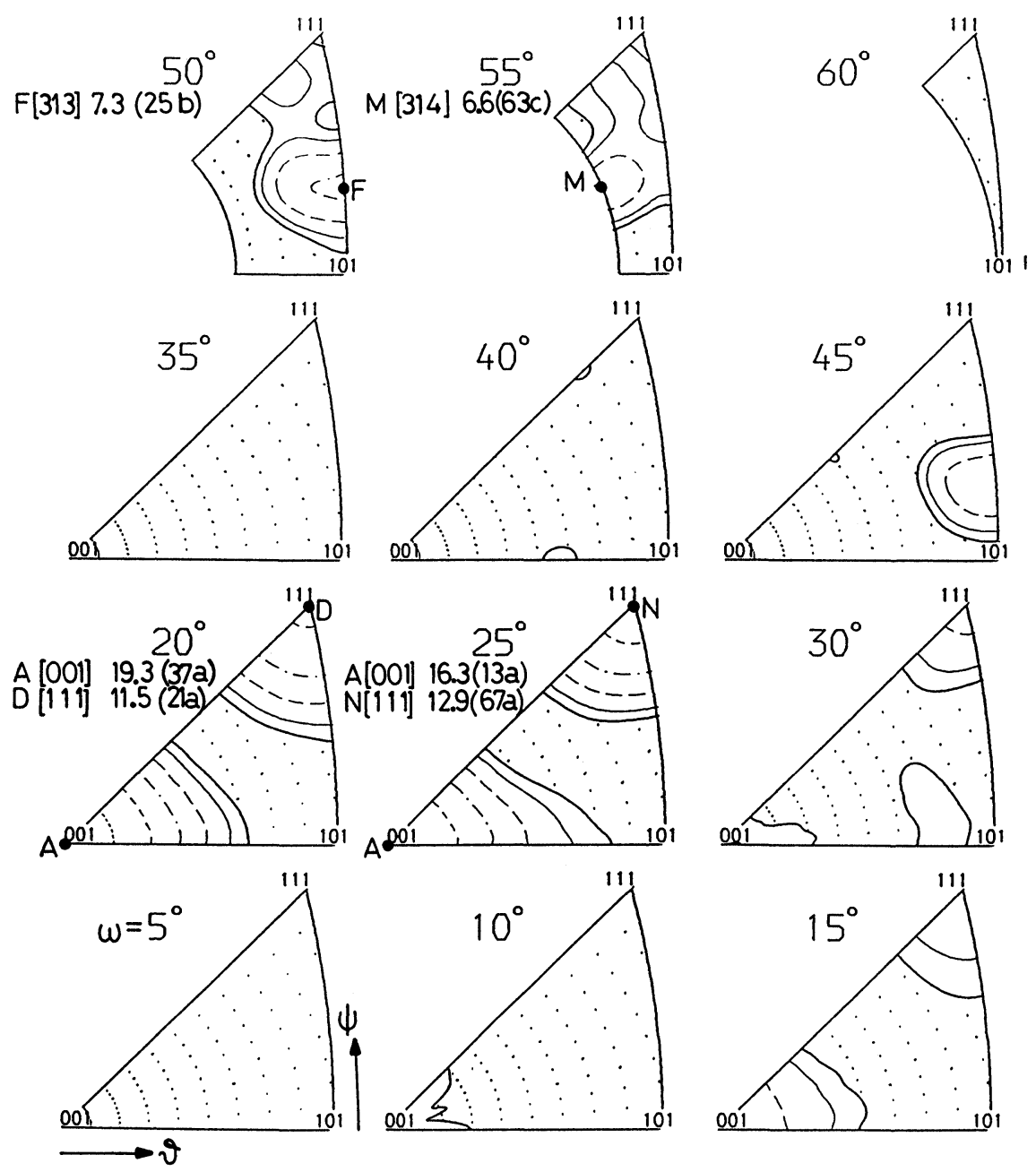

Figure 2 Misorientation distribution function of the largest recrystallised grains in tensile deformed copper single crystals after annealing $(\langle 100\rangle$-oriented crystals, $10 \%$ elongation, annealing temperature $750 \mathrm{~K} ; \mathrm{MDF}$ calculated for the data in Table 2, contour lines 1, 2, 4, 7, 11, 16, Regions under the level 1. are dotted. Maxima marked by: A, B, etc., axis notation, value of the MDF, value of $\Sigma$ ).

tendency to irregular distribution. In every case, at angles of rotation less than $25^{\circ}$, the $\langle 100\rangle$ direction proves to be the preferred axis of rotation. For larger angles of rotation the axis of rotation is displaced in the direction of the symmetry line $\langle 101\rangle-\langle 111\rangle$. A prominent maximum is found for all $\langle 100\rangle$ oriented samples at a rotation angle of $50^{\circ}$ with the axis of rotation close to the $\langle 331\rangle$ direction. These rotations also occur in the $\langle 111\rangle$ samples. Upon increasing the angle of rotation to $55^{\circ}$, the rotational axes near $\langle 331\rangle$ are still preferred, yet one may observe a tendency for the maximum to broaden in the direction $\langle 256\rangle$. Indeed, for the $10 \%$ extended $\langle 100\rangle$ samples the maximum itself is displaced in this 

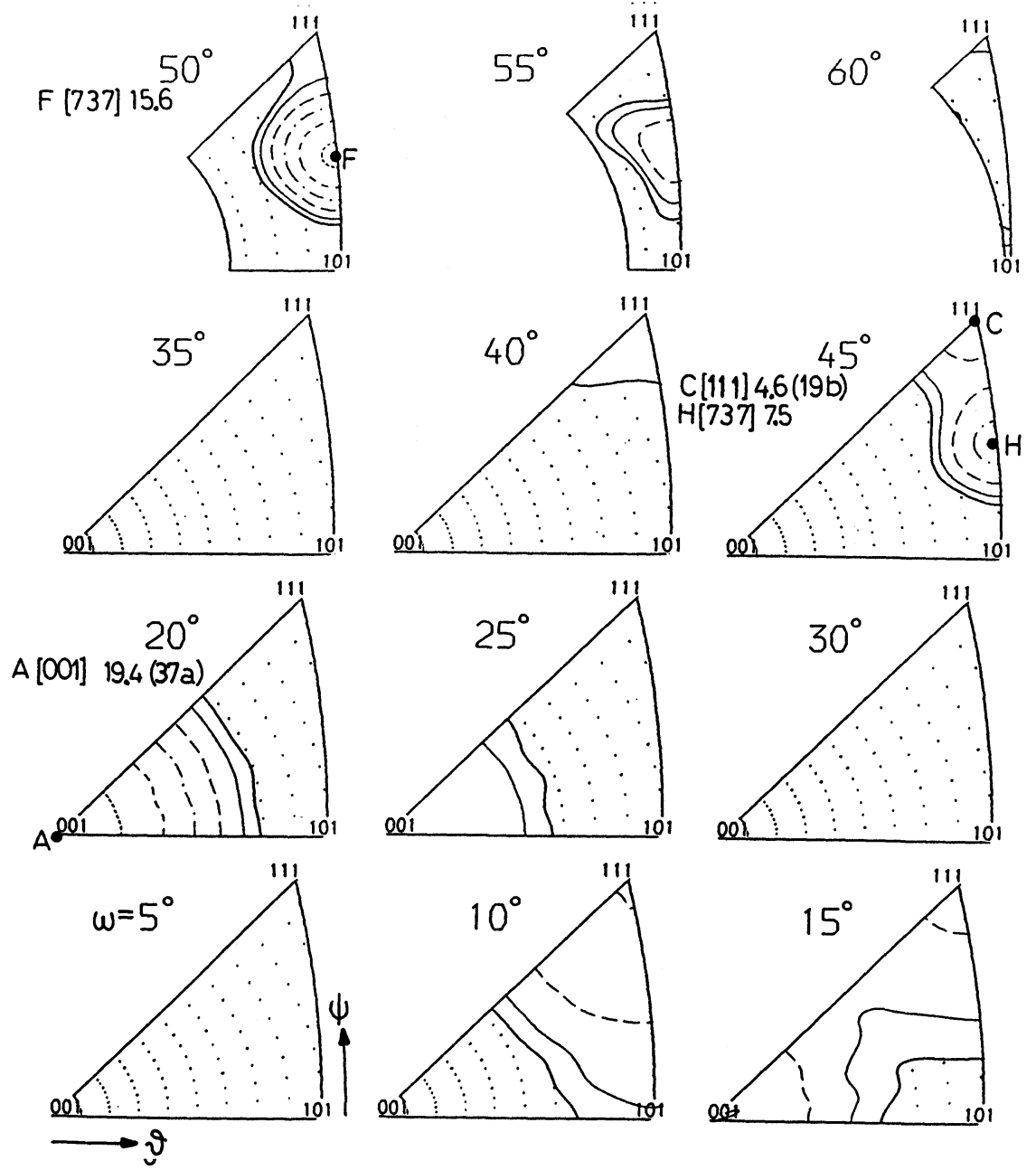

Figure 3 Misorientation distribution function of the largest recrystallised grains in tensile deformed copper single crystals after annealing $(\langle 100\rangle$-oriented crystals, $20 \%$ elongation, annealing temperature $1080 \mathrm{~K}$; MDF calculated for the data in Table 3, contour lines 1, 2, 4, 7, 11, 16, Regions under the level 1. are dotted. Maxima marked by: A, B, etc., axis notation, avlue of the MDF, value of $\Sigma$ ).

direction. Angles of rotation of $60^{\circ}$ only occur in the $20 \%$ deformed $\langle 100\rangle$ samples (annealing temperature $750 \mathrm{~K}$ ) and in the $\langle 111\rangle$ samples.

\section{DISCUSSION}

Evaluation of the individual data using the MDF shows that the results of the recrystallisation experiments on deformed copper single crystals can only be 

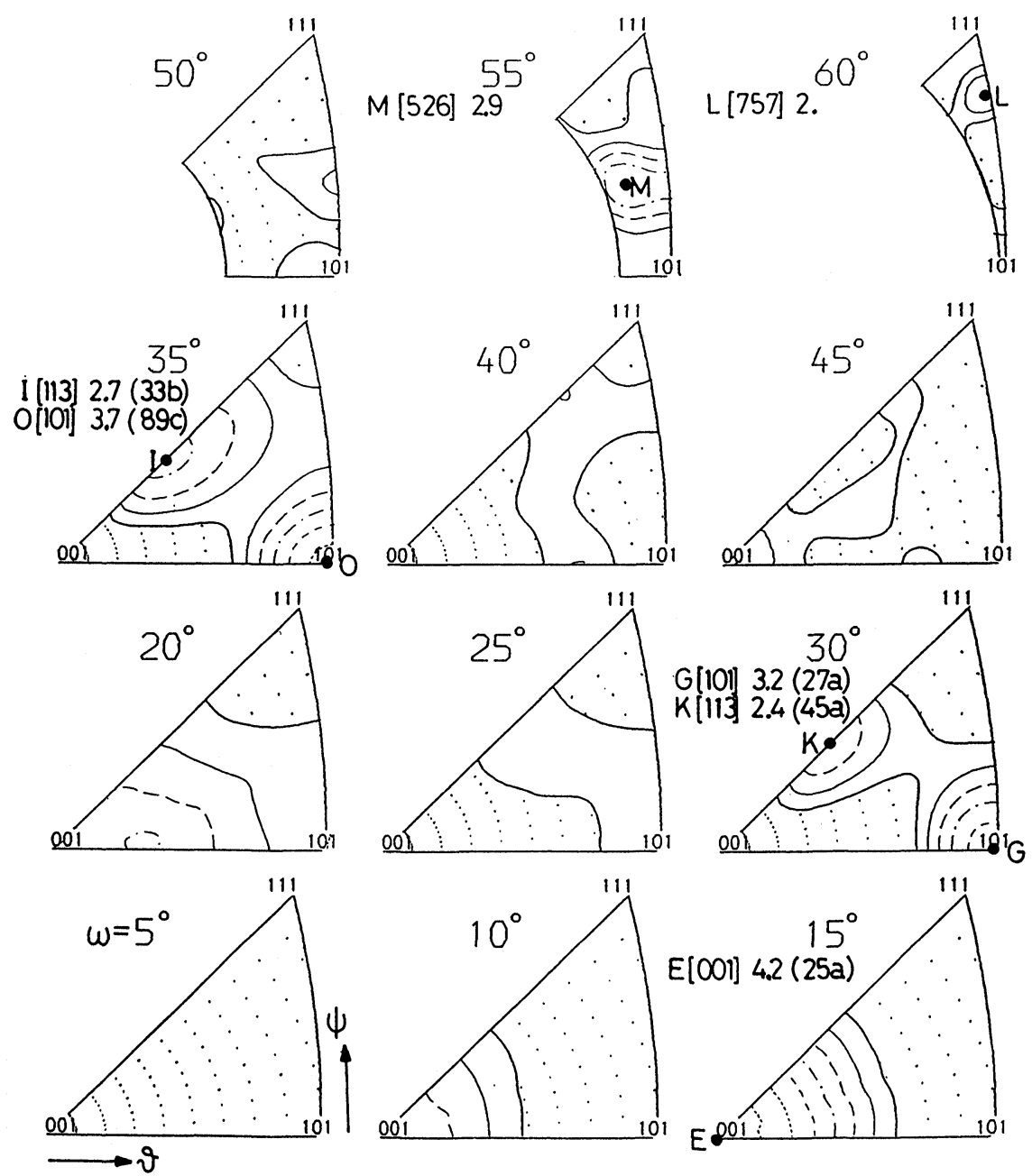

Figure 4 Misorientation distribution function of the largest recrystallised grains in tensile deformed copper single crystals after annealing $(\langle 111\rangle$-oriented crystals, $4 \%$ elongation, annealing temperature $750 \mathrm{~K} ; \mathrm{MDF}$ calculated for the data in Table 4, contour lines 1, 2, 4, 7, 11, 16, Regions under the level 1. are dotted. Maxima marked by: A, B, etc., axis notation, value of the MDF, value of $\Sigma$ ).

correctly described by a larger number of orientation relationships. It is necessary to investigate to what extent the orientation relationships important to the recrystallisations process can be approximated by coincidence orientation relationships. Coincidence grain boundaries are noticeably different from usual grain boundaries with respect to grain boundary energy and mobility in the event of impurities (Rutter and Aust, 1965; Maurer, 1987). The significance of coincidence grain boundaries for recrystallisation has been described elsewhere (Berger et al., 1988).

In accordance with the work of Klement et al. (1988), an initial attempt to 
describe the MDF maxima was made using coincidence orientation relationships with maximum $\Sigma$ values of 25 . However, with these restrictions the characterisation of the results by coincidence orientation relationships proved to be unsatisfactory. For example, the axes of rotation found at angles of rotation of $50^{\circ}$ on or near the symmetry line $\langle 101\rangle-\langle 111\rangle$ cannot be adequately approximated, since for $\Sigma=25$ the $\langle 221\rangle$ and the $\langle 331\rangle$ directions each can only once act as an axis of rotation.

As a result of these difficulties a new characterisation of the MDF maxima followed, with the aid of coincidence orientation relationships having $\Sigma$ values up to 101 . The results compiled in Tables 5.1 to 5.4 show that, on this basis, all the MDF maxima can be very accurately described by coincidence orientation relationships. The tables only show those MDF maxima to which more than one

Table 5.1 Idealisation of the observed orientation relationships by coincidence orientation relationships (MDF calculated for the data in Table 1)

\begin{tabular}{lcl}
\hline $\begin{array}{l}\text { Observed orientation } \\
\text { relationship }\end{array}$ & $\begin{array}{l}\text { Value of } \\
\text { the MDF }\end{array}$ & $\begin{array}{l}\text { Ideal coincidence } \\
\text { orientation relationship }\end{array}$ \\
\hline E $15^{\circ}\langle 100\rangle$ & 8.6 & $\Sigma 25 a\left(16.3^{\circ}\langle 100\rangle\right)$ \\
A $20^{\circ}\langle 100\rangle$ & 11.9 & $\sum 37 a\left(18.9^{\circ}\langle 100\rangle\right)$ \\
A $25^{\circ}\langle 100\rangle$ & 3.8 & $\Sigma 13 a\left(22.6^{\circ}\langle 100\rangle\right)$ \\
B $30^{\circ}\langle 111\rangle$ & 2.5 & $\sum 13 b\left(27.8^{\circ}\langle 111\rangle\right)$ \\
J $45^{\circ}\langle 331\rangle$ & 5.2 & $\Sigma 35 b\left(43.2^{\circ}\langle 331\rangle\right)$ \\
F $50^{\circ}\langle 331\rangle$ & 7.9 & $\Sigma 25 b\left(51.7^{\circ}\langle 331\rangle\right)$ \\
\hline
\end{tabular}

Table 5.2 Idealisation of the observed orientation relationships by coincidence orientation relationships (MDF calculated for the data in Table 2)

\begin{tabular}{lll}
\hline $\begin{array}{l}\text { Observed orientation } \\
\text { relationship }\end{array}$ & $\begin{array}{l}\text { Value of } \\
\text { the MDF }\end{array}$ & $\begin{array}{l}\text { Ideal coincidence } \\
\text { orientation relationship }\end{array}$ \\
\hline $\mathrm{A} 20^{\circ}\langle 100\rangle$ & 19.3 & $\sum 37 a\left(18.9^{\circ}\langle 100\rangle\right)$ \\
$\mathrm{D} 20^{\circ}\langle 111\rangle$ & 11.5 & $\Sigma 21 a\left(21.8^{\circ}\langle 111\rangle\right)$ \\
$\mathrm{A} 25^{\circ}\langle 100\rangle$ & 16.3 & $\Sigma 13 a\left(22.6^{\circ}\langle 100\rangle\right)$ \\
$\mathrm{N} 25^{\circ}\langle 111\rangle$ & 12.9 & $\Sigma 67 a\left(24.4^{\circ}\langle 111\rangle\right)$ \\
$\mathrm{F} 50^{\circ}\langle 331\rangle$ & 7.3 & $\Sigma 25 b\left(51.7^{\circ}\langle 331\rangle\right)$ \\
$\mathrm{M} 55^{\circ}\langle 431\rangle$ & 6.6 & $\Sigma 63 c\left(54.0^{\circ}\langle 431\rangle\right)$ \\
\hline
\end{tabular}

Table 5.3 Idealisation of the observed orientation relationships by coincidence orientation relationships (MDF calculated for the data in Table 3)

\begin{tabular}{lrl}
\hline $\begin{array}{l}\text { Observed orientation } \\
\text { relationship }\end{array}$ & $\begin{array}{l}\text { Value of } \\
\text { the MDF }\end{array}$ & $\begin{array}{l}\text { Ideal coincidence } \\
\text { orientation relationship }\end{array}$ \\
\hline A $20^{\circ}\langle 100\rangle$ & 19.4 & $\Sigma 37 a\left(18.9^{\circ}\langle 100\rangle\right)$ \\
C $45^{\circ}\langle 111\rangle$ & 4.6 & $\Sigma 19 b\left(46.8^{\circ}\langle 111\rangle\right)$ \\
H $45^{\circ}\langle 773\rangle$ & 7.5 & $\Sigma 29 b\left(46.4^{\circ}\langle 221\rangle\right)$ \\
F $50^{\circ}\langle 773\rangle$ & 15.6 & $\Sigma 25 b\left(51.7^{\circ}\langle 331\rangle\right)$ \\
\hline
\end{tabular}


Table 5.4 Idealisation of the observed orientation relationship by coincidence orientation relationships (MDF calculated for the data in Table 4)

\begin{tabular}{lll}
\hline $\begin{array}{l}\text { Observed orientation } \\
\text { relationship }\end{array}$ & $\begin{array}{l}\text { Value of } \\
\text { the MDF }\end{array}$ & $\begin{array}{l}\text { Ideal coincidence } \\
\text { orientation relationship }\end{array}$ \\
\hline $\mathrm{E} 15^{\circ}\langle 100\rangle$ & 4.2 & $\Sigma 25 a\left(16.3^{\circ}\langle 100\rangle\right)$ \\
$\mathrm{G} 30^{\circ}\langle 110\rangle$ & 3.2 & $\Sigma 27 a\left(31.6^{\circ}\langle 110\rangle\right)$ \\
$\mathrm{K} 30^{\circ}\langle 311\rangle$ & 2.4 & $\Sigma 45 a\left(28.6^{\circ}\langle 311\rangle\right)$ \\
$\mathrm{O} 35^{\circ}\langle 110\rangle$ & 3.7 & $\sum 89 c\left(34.9^{\circ}\langle 110\rangle\right)$ \\
$\mathrm{I} 35^{\circ}\langle 311\rangle$ & 2.7 & $\sum 33 b\left(33.6^{\circ}\langle 311\rangle\right)$ \\
$\mathrm{M} 55^{\circ}\langle 652\rangle$ & 2.9 & $\Sigma 63 c\left(54.0^{\circ}\langle 431\rangle\right)$ \\
$\mathrm{L} 60^{\circ}\langle 775\rangle$ & 2.0 & $\Sigma 57 a\left(60.7^{\circ}\langle 553\rangle\right)$ \\
\hline
\end{tabular}

measured value is assigned. In the majority of cases the axes of rotation are coincident. Moreover, this evaluation also shows that the coincidence orientation relationships $\Sigma 13 a, \Sigma 19 b, \Sigma 21 a, \Sigma 23$, and $\Sigma 25 b$ used by Klement at al. (1988) only in a few cases describe the MDF maxima, i.e. they cannot be universally used to characterise the results, as had originally been supposed. According to Table 5 the largest MDF maxima can be represented by $\Sigma 21 a\left(21.8^{\circ}\langle 111\rangle\right)$, $\Sigma 25 a(16.3\langle 100\rangle), \Sigma 25 b\left(51.7^{\circ}\langle 331\rangle\right), \Sigma 29 b\left(46.4^{\circ}\langle 221\rangle\right), \Sigma 37 a\left(18.9^{\circ}\langle 100\rangle\right)$ and $\Sigma 67 a\left(24.4^{\circ}\langle 111\rangle\right)$. Nevertheless, these orientation relationships do not occur equally in all three sets of $\langle 100\rangle$ samples. In all three cases the $\Sigma 25 b$ and the $\Sigma 37 a$ orientation relationships turned out to be dominant.

The effect of the sample treatment on preferential occurrence of orientations is indicated above all by the results obtained with the $\langle 111\rangle$ samples. The low degree of deformation of $4 \%$ chosen for this sample type results, on the one hand, in the uniform distribution of the orientation relationships on the individual MDF maxima as already described, and on the other hand, it suppresses the $\Sigma 25 b$ orientation relationship favoured by all $\langle 100\rangle$ samples. The general absence of the $\Sigma 23$ orientation relationship in the $\langle 111\rangle$ samples observed by Klement et al. (1988) can be explained by the altered evaluation method. As mentioned, the idealisation of certain orientation relationships occurred under the assumption of a maximum $\Sigma$ value of 25 , where by an error of $10^{\circ}$ was tolerated. Under these presuppositions a series of orientation relationships with $\Sigma 23$ were idealised which were assigned to various maxima of the MDF on repeated evaluation.

Furthermore, the improved evaluation of the data shows that recrystallised grains with a $40^{\circ}\langle 111\rangle$ orientation relationship to the strained structure in pure copper are not distinguished by a particularly strong growth. The same conclusion holds for grains with a $30^{\circ}\langle 111\rangle$ orientation relationship, since the MDF shows a weak maximum at the appropriate site in the misorientation space for a set of $\langle 100\rangle$ samples only. According to investigations by Möhlmann (1966) on silver, recrystallised grains with a $30^{\circ}\langle 111\rangle$ orientation relationship to the matrix exhibit preferential growth.

To sum up: the description of the orientation relationships which dominate the recrystallisation process using coincidence relationships is justified, then as now. However a $\Sigma$ value of 25 is not a meaningful upper limit since the characterisation of certain orientation relationships requires higher values. It is not clear what are 
the physical reasons for the occurrence of orientation relationships with large $\Sigma$ values. Berger et al. (1988) were actually able in some cases to identify the grain boundaries of preferentially growing grains as being unequivocally of low energy. The current understanding of grain boundaries does however not permit these sort of conclusions to be drawn for grain boundaries with high $\Sigma$ values.

\section{Acknowledgement}

One of the authors (K.S.) gratefully acknowledges financial support by the Deutsche Forschnungsgemeinschaft.

\section{References}

Berger, A. (1986). Hochspannungs-Elektronenmikroskopie der Rekristallisation von CuPEinkristallen. Universität Göttingen: Doctoral thesis.

Berger, A., Wilbrandt, P.-J., Ernst, F., Klement, U. and Haasen, P. (1988). On the Generation of New Orientations During Recrystallization: Recent Results on the Recrystallization of TensileDeformed fcc Single Crystals. Progress in Materials Science, 32, 1-95.

Bunge, H. J. (1982). Texture Analysis in Materials Science. London, Butterworths.

Bunge, H. J. and Weiland, H. (1988). Orientation Correlation in Grain and Phase Boundaries. Textures and Microstructures, 7, 231-263.

Ernst, F. and Wilbrandt, P.-J. (1984). Growth Selection Experiments in Tensile Deformed $\langle 100\rangle$-Oriented Copper Single Crystals. In Proceedings of the ICOTOM 7, edited by C. M. Brakman, P. Jongenburger and E. J. Mittemeyer, pp 233-238. Zwijndrecht: The Netherlands Society for Materials Science.

Ernst, F. (1984). Rekristallisationsexperimente in $\langle 100\rangle$-zugverformten Kupfer-Einkristallen mit künstlicher Keimbildung. Universität Göttingen: Diploma thesis.

Frank, F. C. (1988). Orientation Mapping. Metallurgical Transactions, 19A, 403-408.

Haeßner, F., Pospiech, J. and Sztwiertnia, K. (1983). Spatial Arrangement of Orientations in Rolled Copper. Materials Science and Engineering, 57, 1-14.

Hirsch, J. (1988). Untersuchung der primären Rekristallisation und ihrer Mechanismen mit Hilfe der Texturanalyse. RWTH Aachen: Inaugural dissertation.

Klement, U. (1987). Rekristallisationsexperimente an $\langle 111\rangle$-zugverformten Kupfereinkristallen. Universität Göttingen: Diploma thesis.

Klement, U. and Wilbrandt, P.-J. (1988). Recrystallization Experiments in Tensile Deformed 〈111〉-Oriented Copper Single Crystals. In Proceedings of the ICOTM 8, edited by J. S. Kallend and G. Gottstein, pp 591-596. Warrendale: The Metallurgical Society.

Klement, U., Ernst, F. and Wilbrandt, P.-J. (1988). Recrystallization Experiments in Tensile Deformed $\langle 100\rangle$-Oriented Copper Single Crystals. Textures and Microstructures, 8 \& 9, 383-400.

Liebmann, B., Lücke, K. and Masing, G. (1956). Untersuchungen über die Orientierungsabhängigkeit der Wachstumsgeschwindigkeit bei der primären Rekristallisation von Aluminium-Einkristallen. Zeitschrift für Metallkunde, 47, 57-63.

Mackenzie, J. K. (1958). Second Paper on Statistics Associated with the Random Disorientation of Cubes. Biometrika, 45, 229-240.

Maurer, R. (1987). Improved Technique for the Determination of Low Energy Boundaries by the Rotating-Sphere-on-a-Plate Method: Results for Grain Boundaries in the Cu/Ni System. Acta Metallurgica, 35, 2557-2565.

Möhlmann, U. (1966). Wachstumsauslese bei der Rekristallisation verformter Silbereinkristalle. RWTH Aachen: Doctoral thesis.

Pospiech, J. and Lücke, K. (1975). The Rolling Textures of Copper and $\alpha$-Brasses Discussed in Term of the Orientation Distribution Function. Acta Metallurgica, 23, 997-1007.

Pospiech, J., Sztwiertnia, K. and Haeßner, F. (1986). The Misorientation Distribution Function. Textures and Microstructures, 6, 201-215.

Ruer, D. (1976). Methode Vectorielle d'Analyse de la Texture. Thése d'Etat $n^{\circ}$ A013225, C.N.R.S., Paris. 
Rutter, J. W. and Aust, K. T. (1965). Migration of $\langle 100\rangle$ Tilt Grain Boundaries in High Purity Lead. Acta Metallurgica, 13, 181-186.

Senna, M. and Lücke, K. (1976). Formation of Recrystallization Textures in Tensile Deformed Aluminium Single Crystals. Zeitschrift für Metallkunde, 67, 752-757.

Wilbrandt, P.-J. (1987). Untersuchung der Rekristallisation von zugverformten Kupfereinkristallen im Hochspannungs-Elektronemikroskop. Universität Göttingen: Doctoral thesis.

Wilbrandt, P.-J. and Haasen, P. (1980a). HVEM of the Recrystallization of Tensile Deformed $\langle 100\rangle$-Oriented Copper Single Crystals. Part I: The Deformed State. Zeitschrift für Metallkunde, 71, 273-278.

Wilbrandt, P.-J. and Haasen, P. (1980b). HVEM of the Recrystallization of Tensile Deformed $\langle 110\rangle$-Oriented Copper Single Crystals. Part II: The Recrystallized State. Zeitschrift für Metallkunde, 71, 385-395. 